\title{
MICRO NEEDLING VERSUS CARBON DIOXIDE FRACTIONAL LASER IN MANAGEMENT OF ACNE SCARS
}

\author{
Shanza Obaid, Nadia Iftikhar, Asher Mashhood*, Ayesha Khokhar, Zarnab Zainab, Kanza Aftab \\ Pak Emirates Military Hospital/National University of Medical Sciences (NUMS) Pakistan, *Combined Military Hospital/National University of Medical Sciences \\ (NUMS) Rawalpindi Pakistan
}

\begin{abstract}
Objective: To compare the effectiveness of carbon dioxide fractional laser with micro needling in acne scarring. Study Design: Quasi experimental study.

Place and Duration of Study: Department of Dermatology, Pak Emirates Military Hospital Rawalpindi, from Jun 2019 to Mar 2020.

Methodology: Overall 40 patients with acne scars assessed by consultant dermatologist were made part of study. The patients were divided into two treatment groups through lottery method. Group A, was managed by micro needling technique, while Group B was managed by carbon dioxide fractional laser, each to be done monthly for a total of three sessions. The response was measured by the dermatologist and patients in both the groups. The side effects were also compared in both the groups.

Results: Out of 40 patients with acne scars included in study, 17 (42.5\%) underwent micro-needling while $23(57.5 \%)$ underwent carbon dioxide fractional laser treatment after randomization. Thirty $(75 \%)$ patients were female while $10(25 \%)$ were male. The patients with acne scars responded better in carbon dioxide fractional laser group as compared to micro needling in opinion of dermatologists $(p$-value $=0.01)$ and also patients themselves ( $p$-value $=0.03)$. Side effects were significantly higher in carbon dioxide fractional laser group as compared to micro needling $(p$-value $=0.02)$.

Conclusion: Significant number of patients respond well to carbon dioxide fractional laser treatment and the response included both expert opinion and patients own opinion, but adverse effects were seen more in same group. Therefore, better response but at the cost of more adverse effects was noted.
\end{abstract}

Keywords: Acne vulgaris, Carbon dioxide, Laser, Micro-needling.

How to Cite This Article: Obaid S, Iftikhar N, Mashhood A, Khokhar A, Zainab Z, Aftab K. Micro Needling Versus Carbon Dioxide Fractional Laser in Management of Acne Scars. Pak Armed Forces Med J 2021; 71(6): 2095-2098. Doi: https://doi.org/10.51253/pafmj.v71i6.5444

This is an Open Access article distributed under the terms of the Creative Commons Attribution License (https://creativecommons.org/licenses/by-nc/4.0/), which permits unrestricted use, distribution, and reproduction in any medium, provided the original work is properly cited.

\section{INTRODUCTION}

Acne vulgaris is a common chronic inflammatory disease related to pilo-sebaceous unit. It is one of the well known skin illnesses and it influences $80 \%$ of the young adult population. ${ }^{1}$ Acne generally has an extended course with severe or insidious relapse or reappearance with the passage of time. Pathogenesis of acne involves various factors which include propionibacterium acnes activity, excess sebum production, androgenic stimulation, follicular hypercornification, various inflammatory cells response and cytokine activation. ${ }^{2}$

Acne leads to scarring which has a great physical and psychological impact on the patients. ${ }^{3}$ Prevention of acne scars development can be done by controlling skin inflammation during acne outbreak. Despite appropriate and effective primary prevention of scarring, it occurs in $95 \%$ of all acne patients. There are two basic forms of acne scars, Hypertrophic scars and Atrophic scars. Atrophic scars arefurther sub classified into

Correspondence: Dr Shanza Obaid, House\#4, Mochh House, OPP AFIRM, RA Bazar, Rawalpindi Pakistan

Received: 06 Oct 2020; revision received: 22 Nov 2020; accepted: 25 Nov 2020 ice pick, box scars and rolling scars.

Various modalities have been researched and used in clinical practice to manage the scars related to acne lesions. ${ }^{4}$ These modalities include chemical peeling laser treatment, punch grafting technique, fat transplantation, other tissue augmentation agents, micro needling, subcission and combined therapies. In last decade laser treatment has been gaining a lot of importance and making place in administration of the acne scars. ${ }^{5}$ In 2018, Kravas et al, published a review of 59 studies and concluded that numerous energy based devices ( $\mathrm{CO} 2$ ablative laser, RF, Non ablative fractional thermolysis) have been utilized with fluctuating degrees of efficacy and altogether different safety profiles. However, no conclusive evidence exists regarding the outcome of various interventions. Additionally, no standardized scale is accessible for acne scarring, which leads to fluctuation in assessment and understanding of data in various investigations. ${ }^{6}$

Harris et al, in 2015 published a review of skin needling and came up with the conclusion that there is reasonable evidence to recommend that skin needling 
is advantageous and benign for treating acne scarring. However, double-blinded, randomized controlled trials are required to make more definitive conclusions. ${ }^{7}$ In 2019, Zayed et al, performed a study with the objective to assess and compare the clinical and histopathological outcome of micro-needling versus ablative fractional $\mathrm{CO} 2$ laser targeting atrophic post-burn scars. According to them, ablative fractional $\mathrm{CO} 2$ laser is far more efficacious than micro-needling in the management of atrophic post-burn scars in terms of histopathological outcome ( $p$-value 0.083 ); nevertheless, a substantial growth in elastic fiber deposition was shown by micro-needling and therefore it can be termed as an encouraging therapeutic method when additional treatment modalities are combined with it. ${ }^{8}$ Qian et $a l$, in 2012 after studying 31 patients with acne scarring concluded that high-energy pulsed and cool-scanned fractional ablative $\mathrm{CO} 2$ laser system is safe and effective for facial atrophic acne scarring. Improvement in scarring was noted in the majority of patients with minimal discomfort and minimal downtime. Out of $12.9 \%$ patients showed excellent improvement and $38.71 \%$ showed good to fair response. Continued improvement over time was also an important clinical finding. ${ }^{9}$

Afzal et al, studied effectiveness of micro-needling in post acne scarring and came up with the findings which showed that that micro-needling is aproductive tool for aesthetic enhancementof post acne scarring. ${ }^{10}$ Doctors dealing with skin conditions in Pakistan often have to rely on guidelines based on researches conducted in other parts of the world due to limited local data. We designed this study with the objective to compare of the efficacies of $\mathrm{CO} 2$ laser versus micro needling in acne scarring at dermatology department of a teaching hospital of Pakistan.

\section{METHODOLOGY}

This study was conducted at the Department of Dermatology in Pakistan Emirates Military Hospital Rawalpindi, from June 2019 to March 2020. The World Health Organisation (WHO) sample size calculator was used to calculate the sample size with a population prevalence proportion of patients improving with micro-needling as $0.9 \% .{ }^{11}$ The non-probability consecutive sampling technique was used for gathering the samples for this study.

Inclusion Criteria: Patients of both genders with acne scars diagnosed by consultant dermatologist between the age of 18 and 55 were part of the study.
Exclusion Criteria: Patients with active/recurrent herpes infection or the patients with a previous complaint of hypertrophic scarring/keloid, patients who have used oral retinoid in last six months were excluded. Patients who underwent any treatment for the scars in last one year were pregnant and lactating women and patients refusing consent to participate in the study were also excluded from the study.

For getting the ethical approval for the current study, Ethical review board committee of the hospital was approached. Ethical approval was granted (ltr no. A/28/EC/37/19). Before commencement of the study, comprehensive description of the study was given to all the participants and afterwards written informed consentwas taken from them. Patients were distributed into two groups A and B through lottery method. Group A was managed by the standard micro needling technique procedure. ${ }^{12}$ Before procedure, face was wiped down with alcohol swab and topical anesthetic cream was applied for forty minutes. Micro needling was performed with sterile needles of depth $2 \mathrm{~mm}$ in crisscross pattern. Patient was prescribed topical antibiotic application for complete three days and sun protection was advised. Group B was managed with the standard $\mathrm{CO} 2$ fractional laser treatment. ${ }^{13}$ Energy of 30 milli joules and ablation depth of $1.6 \mathrm{~mm}$ was set for each session. Total three sessions were performed, one month apart for both the procedures. Response was recorded by both the patients and an independent dermatologist assessor one month after the last session. Expert categorized it on the basis of percentage of improvement. Response was classified as less than $25 \%$ (poor), $25-50 \%$ (fair), $50-75 \%$ (good) and $>75 \%$ (excellent) response. Patient rated their satisfaction from 0-10 and $>6$ was regarded as sufficient satisfaction for the procedure. Side effects were also recorded in each group which from previous studies were expected to be prolonged erythema, photosensitivity, post-inflammatory hyperpigmentation and hypertrophic scar. ${ }^{14}$

Characteristics of participants and the distribution of the patients in two treatment groups were recorded. Chi-square test was applied to look for the correlation of physicians grading of response, patient's satisfaction and presence of adverse effectsin both treatment groups. Statistical Package for the social sciences (SPSS) version 23 was used for data analysis. The $p$ value of $\leq 0.05$ was considered significant.

\section{RESULTS}

Total 40 patients were recruited in the study. Out of 40 patients with acne scars included in the study, 
17 (42.5\%) underwent micro-needling while 23 (57.5\%) underwent $\mathrm{CO} 2$ fractional laser treatment after the randomization. Table-I shows that $30(75 \%)$ patients were male while $10(25 \%)$ were female. Table-II shows, application of chi-square test revealed that $\mathrm{CO} 2$ fractional laser group showed a statistically significant better response in expert opinion ( $p$-value $=0.015)$ as well as opinion of patients themselves ( $p$-value $=0.03$ ), but side effects were also more in the $\mathrm{CO} 2$ fractional laser group ( $p$-value $<0.024)$. Post inflammatory hyper-pigmentation was themost frequent adverse effect seenin the $\mathrm{CO} 2$ fractional laser group (4 patients-17.4\%). Results showed that satisfactory response in expert opinion was seen in $17(73.9 \%)$ patients of $\mathrm{CO} 2$ fractional laser group and $5(41.6 \%)$ patients of micro needling group.

\begin{tabular}{|c|c|}
\hline Characteristics & n (\%) \\
\hline \multicolumn{2}{|l|}{ Age (years) } \\
\hline $\begin{array}{l}\text { Mean } \pm \text { SD } \\
\text { Range (Min-Max) }\end{array}$ & $\begin{array}{c}28.24 \pm 3.122 \\
18-55 \text { years } \\
\end{array}$ \\
\hline \multicolumn{2}{|l|}{ Gender } \\
\hline $\begin{array}{l}\text { Male } \\
\text { Female }\end{array}$ & $\begin{array}{l}30(75 \%) \\
10(25 \%) \\
\end{array}$ \\
\hline \multicolumn{2}{|l|}{ Treatment Received } \\
\hline $\begin{array}{l}\text { Micro-Needling } \\
\text { CO2 Fractional Laser }\end{array}$ & $\begin{array}{l}17(42.5 \%) \\
23(57.5 \%)\end{array}$ \\
\hline
\end{tabular}

Table-II: Outcome of various variables studied in the analysis.

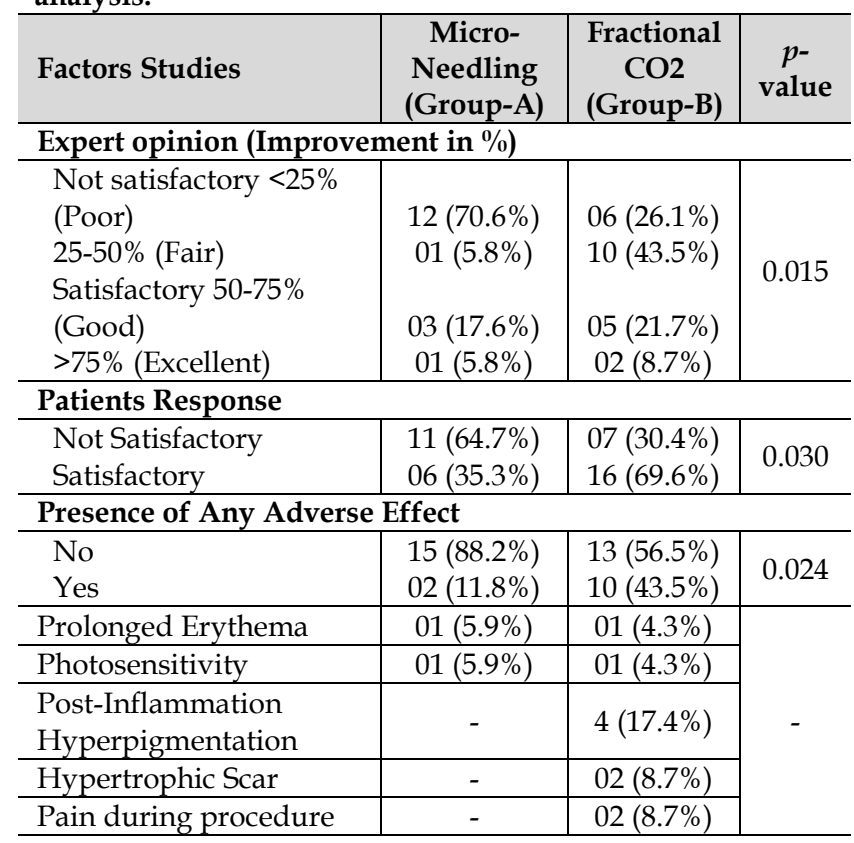

\section{DISCUSSION}

Patients with acne vulgaris use a lot of medical and even alternate medicine treatment in order to get rid of this chronic and recurring skin condition.5,15
Previous epidemiological studies done in our part of the world have concluded that acne vulgaris has been a fairly common diagnosis in dermatology clinics especially for the young population and they have different beliefs regarding its etiology and management. ${ }^{15}$ Recent advances in medical science especially various laser treatments have revolutionized the dermatology management plans for various lesions. Scarring conditions which were once considered most difficult to manage have now been managed adequately in most of the cases with various modalities. Due to limited data in our set up we designed this study to compare the efficacies of $\mathrm{CO} 2$ laser versus micro needling in acne scarring at dermatology department of a teaching hospital of Pakistan.

Bhargava et al. ${ }^{16}$ in 2018 conducted a systematic review which included a critical assessment of the evidence pertinent to various modalities used for treating acne scarring i.e resurfacing (abrasion, peels, needling, ablative lasers), lifting (subcission), volumization (filler, PRP), tightening (fractional non ablative lasers, fractional RF) and surgical options (punch elevation). Detailed evaluation of result of 89 studies also supported that lasers and radiofrequency have great efficacy in atrophic acne scarring. Other modalities can also be utilized as an adjunct, the choice of which is dependent on the grade, type and extent of atrophic scars. Radiofrequency and micro needling, which are minimally invasive procedures have better outcomes with insignificant risks in patients with sensitive ordark skin types. ${ }^{16}$ Results of our study were somewhat similar with the recommendations of metanalysis conducted by Bhargava et al, and $\mathrm{CO}_{2}$ fractional laser had more efficacy as compared to micro-needling.

The most common adverse effect seen in our patients was post inflammatory hyperpigmentation and that too with $\mathrm{CO} 2$ fractional laser therapy. Bernstein et al. in 1997 did a similar study and had findings similar to ours stating that althoughrisk of adverse effects was usually very low for $\mathrm{CO}_{2}$ laser resurfacing, but the incidence of pigmentary changes was 19.2\% after $\mathrm{CO} 2$ fractional laser. Hyperpigmentation was seen in $2.8 \%$ of patients. However, there was noteworthy and formerly unreported risk of hypopigmentation (16.3\% patients) in such patients. ${ }^{17}$

Saoji et al, in 2017 compared CO2 fractional laser and dermaroller (a form of microneedling) for treating acne scarring in Indianethnicity and concluded that fractional photothermolysis is possibly the only monotherapy thatproffer the highest degree of scar reduc- 
tion. Excellent response was seen in $20 \%$ patients of $\mathrm{CO} 2$ fractional laser group and $12 \%$ patients of micro needling group. However derma roller has lesser down time and very few complications as compared to $\mathrm{CO} 2$ fractional laser which has higher downtime and grave complications of post inflammatory hyperpigmentation. ${ }^{18}$

Badheka et al, in 2016 did a study to compare the efficacy of subcission, $\mathrm{CO}_{2}$ fractional laser and dermaroller (microneedling) in acne scars and concluded that outstanding response was seen in $13.33 \%, 20 \%$ and $6.7 \%$ patients in the above treatment groups respectively. He concluded that $\mathrm{CO} 2$ laser was better than subcission which in turn was better than dermaroller in terms of efficacy. ${ }^{14}$ However he also concluded that time tested procedures;like subcission if done effectively and appropriately have excellent response and is analogous to newer and expensive modalities like $\mathrm{CO} 2$ fractional laser. ${ }^{14}$ Our results showed that $\mathrm{CO} 2$ fractional laser emerged as superior treatment from efficacy point of view but at the cost of more side effects as compared to micro needling (which is similar to derma roller).

\section{LIMITATION OF STUDY}

This study has few limitations as well. Sample size was small hindering the generalizability of this study to local population. Patients could not be blinded to which treatment group they belong. Addressing of these limitations in future studies may generate better results.

\section{CONCLUSION}

Significant number of patients respond well to $\mathrm{CO} 2$ fractional laser treatment and the response included both the expert opinion and patients own opinion, but adverse effects were also seen more in the same group. Therefore, better response may be at cost of more adverse effects.

\section{Conflict of Interest: None.}

\section{Authors' Contribution}

SO: Data analysis, NI: Concept, design, AM: Data collection, AK: Data collection, ZZ: Data interpretation, KA: Data interpretation

\section{REFERENCES}

1. Connolly D, Vu HL, Mariwalla K, Saedi N. Acne scarringpathogenesis, evaluation, and treatment options. J Clin Aesthet Dermatol 2017; 10(9): 12-23.
2. Gozali MG, Zhou B. Effective treatments of atrophic acne scars. J Clin Aesthet Dermatol 2015; 8(5): 33-40.

3. Fabbrocini G, Annunziata MC, Arco VD, Vita VD, Lodi G, Mauriello MC, et al. Acne scars: pathogenesis, classification and treatment. Dermatol Res Pract 2010; 2010(1): 893080doi.

4. Oon HH, Wong SN, Aw DCW, Cheong WK, Goh CL, Tan HH. Acne management guidelines by the dermatological society of Singapore. J Clin Aesthet Dermatol 2019; 12(7): 34-50.

5. Seago M, Shumaker PR, Spring LK, Alam M, Al-Niaimi F, Rox Anderson $\mathrm{R}$, et al. Laser treatment of traumatic scars and contractures: 2020 international consensus recommendations. Lasers Surg Med 2020; 52(2): 96-116.

6. Kravvas G, Al-Niaimi F. A systematic review of treatments for acne scarring. Part 2: energy-based techniques. Scars Burn Heal 2018; 4(1): 2059513118793420.

7. Harris AG, Naidoo C, Murrell DF. Skin needling as a treatment for acne scarring: An up-to-date review of the literature. Int J Womens Dermatol 2015; 1(2): 77-81.

8. Zayed AA, Mashaly HM, Raheem HMA, El-Nabarawy E, ElHawary MS, Shaker OG, et al. Microneedling versus fractional $\mathrm{CO} 2$ laser in the treatment of atrophic postburn scars. J Egypt Womens Dermatol Soc 2019; 16(3): 37-42.

9. Qian H, Lu Z, Ding H, Yan S, Xiang L, Gold MH. Treatment of acne scarring with fractional $\mathrm{CO} 2$ laser. J Cosmet Laser Ther. 2012; 14(4): 162-165.

10. Afzal FF, Ahmad S, Mehrose MY, Saleem M, Yousaf MA, Mujahid AM, et al. Efficacy of micro-needling on post acne scars. J Ayub Med Coll Abbottabad 2019; 31(3): 336-339.

11. Ochi H, Tan L, Tan WP, Goh CL. Treatment of facial acne scarring with fractional carbon dioxide laser in asians, a retrospective analysis of efficacy and complications. Dermatol Surg 2017; 43(9): $1137-1143$.

12. El-Domyati M, Barakat M, Awad S, Medhat W, El-Fakahany H, Farag H. Microneedling therapy for atrophic acne scars: an objective evaluation. J Clin Aesthet Dermatol 2015; 8(7): 36-42.

13. Petrov A, Pljakovska V. Fractional carbon dioxide laser in treatment of acne scars. Open Access Maced J Med Sci 2016; 4(1): 3842.

14. Badheka AD, Mansuri UU, Solanki RB. A study of efficacy of subcision, micro-needling and carbon dioxide fractional laser for treatment of acne scars. Int J Res Med Sci 2016; 4(7): 26232629.

15. Babar O, Mobeen A. Prevalence and psychological impact of acne vulgaris in female undergraduate medical students of Rawalpindi and Islamabad, Pakistan. Cureus 2019; 11(9): e5722.

16. Bhargava S, Cunha PR, Lee J, Kroumpouzos G. Acne scarring management: systematic review and evaluation of the evidence. Am J Clin Dermatol 2018; 19(4): 459-477.

17. Bernstein LJ, Kauvar AN, Grossman MC, Geronemus RG. The short- and long-term side effects of carbon dioxide laser resurfacing. Dermatol Surg 1997; 23(7): 519-525.

18. Saoji VV, Ganoje MM. Comparative study of fractional CO2 laser and dermaroller in the treatment of atrophic facial acne scars. J Evid Based Med Healthc 2017; 4(94): 5890-5896. 